\title{
Analysis on Characteristics and Value of Dragon Boat Culture
}

\author{
Yingfeng $\mathrm{He}^{1}$ \\ Physical Education Department \\ Shanghai Polytechnic University \\ Shanghai, China \\ heyingfeng@sspu.edu.cn
}

\author{
Qun Cong ${ }^{2}$ \\ Physical Education Department \\ Shanghai Polytechnic University \\ Shanghai, China \\ congqun@sspu.edu.cn
}

\begin{abstract}
Dragon boat culture originates in China and shows a long historical standing. Dragon boat culture is a typical Chinese culture that is extensive and profound. It meets the law of social development with positive factors, which is worth extending and developing strongly so that we can improve the soft power of dragon boat culture. This paper analyzes the characteristics and value of dragon boat culture in order to spread the dragon boat culture all over the world and extend the soft power of Chinese traditional culture.
\end{abstract}

Keywords-Characteristic; Value; Culture; Analysis; Spread

\section{INTRODUCTION}

Dragon boat culture represents patriotism culture in China as it implies a kind of humanistic spirit of love motherland and native people, optimism and marching forward courageously. At present dragon boat culture is spreading all over the world and it has a strong appeal in different time, society and countries, which makes us explore the resource of dragon boat culture further [1], enrich national culture constantly, improve physical and mental health completely and create the wealth of society lastingly. As a result, it is necessary for us to recognize the characteristics and value of dragon boat culture.

\section{CHARACTERISTICS OF DRAGON BOAT CULTURE}

Dragon boat culture can be defined as the culture of competitive sports, festival, totem and water ecology. Its characteristics are as following:

\section{A. Spreading Extensively}

In the course of inheriting and developing the dragon boat culture, more and more people take part in the dragon boat race and feel the atmosphere of dragon boat festival. With the development of the society, the ways and the content of showing dragon boat culture are increasing [2]. What's more, it has been spreading from China to other countries, especially in Southeast Asia and The Pacific Rim countries. Now dragon boat race has gradually become an international sports event and more and more people have recognized the importance of dragon boat festival and enjoy it; most of the people who participate in the competition and festival have accepted the totem culture. In a word, the dragon boat culture gives full expression to its value with the society development and we have to make full use of it to promote culture and economy exchanging, which leads to the dragon boat culture expanding in the world.

Today, as the core component of dragon boat culture, dragon boat race is among the fastest growing of team water sports in the world, with millions of participants in various organizations and clubs in nearly 100 countries. The dragon boat race tells us what is the camaraderie, strength and endurance among participants, and it has become a very popular sport in the world. Now, dragon boat race has been a world competitive game. The First World Dragon-Boat Championships took place in China in 1995, in which 14 teams from other countries and districts took part in various events. The dragon boat race that originated from ancient China now is influencing the world with its special power [3].

\section{B. Diversity}

- Dragon boat race is held in honor of different person in different time. Dragon boat culture is closely connected to dragon boat race. In southern China, the dragon boat race takes place in Lantern Festival. In Xishuangbanna, Yunnan Province of China, it is hosted ten days after Qingming Festival. In Xianyou town, Fujian Province of China, it is held on the thirtieth of the third lunar month in honor of soldiers who swore not to surrender in Yuan dynasty. Besides, in Shuijiang Area, Guizhou Province of China, the Dragon Boat Festival takes place in honor of old person who dove into the water to fought against snake. In short, the dragon boat takes place in honor of different person in different time because of the different traditions.

- Different dragon boats indicate different dragon boat culture. Originally, dragon boat is a sort of canoe with dragon carved. Then the canoe turned to the shape of dragon with dragon head and tail carved, and dragon scales carved in both sides of the dragon boat. Over time, dragon boat race forms a national ceremony and become an important festival that is the symbol of unity, friendship and happiness.

- The number of athletes who join a dragon boat race is different. In china, there are mainly two dragon boat race, that is, 50 athletes and 11 athletes on a dragon boat. 
Later, international dragon boat race arose where there are 23 athletes on a boat.

\section{ANALYSis ON THE VALUE OF DRAGON BoAt CUlture}

\section{A. The Soft Power of Dragon Boat Culture}

When the definition of soft power originally occurs in international relation field, it refers to the ability for some country to obtain influence and attraction through the factors of culture and idea. In recent years, with the economy and society developing lastingly in China, dragon boat culture has possessed the soft power of dragon boat culture in terms of values, which is eliminating the misunderstanding between Chinese and Western Countries on dragon boat culture. Therefore, although the dragon boat culture has been popular with people in China and Southeast Asia countries, the number of people who are attracted by it is increasing significantly in recent years, especially in European Countries, the USA, Australia and so on [4]. The reason why dragon boat culture has a strong appeal to the participants lies in collectivism and positive attitude. In the globalized world today, we should try our best to make the dragon boat culture integrate into world culture so that it can enrich culture diversity and enhance the soft power of dragon boat culture.

- Offer strong support for organizers and participants to spread dragon boat culture and dominate the global contest for soft power dragon boat culture.

- Manage to appeal to new participants from various classes in order to deepen its influence all over the world.

- Cultural exchange between China and other countries can be a representative way of how to spread its soft power.

- As Chinese traditional national culture, dragon boat culture plays a significant role in carrying out the national culture and promoting the development of the soft power of Chinese national culture. Dragon boat culture contributes to improving Chines high national cohesion and the spirit of patriotism, shape citizens' sense of national pride and cultivate team-work spirit of participants.

\section{B. Improving City Development}

Spreading dragon boat culture can contribute to showing the image of a city and setting up a platform of city development. In China, how to seek out the joint between modern culture and traditional culture is the main issue that we need to solve because we can develop the market with huge potentials if we settle the issue. For example, holding dragon boat activities can improve tourism and business development, and become a new growth point of local economy. Take Shanghai Suzhou Greek Dragon Boat Invitational Tournament as an example. In 2017, the 14th invitational tournament consists of 52 teams among 6 groups and more than 800 athletes who come from the different countries and areas take part in the event, which makes the event become a brand event in Shanghai city and promote the cultural communication and the development of the economy and tourism [5].
- Perfect the facilities and regulations of a city and make the city more advanced.

- Strength city's tourism competitive forces and improve economic development

- Set up a platform for leading the city's social and economic development.

- Be helpful to establish a brand image of dragon boat race for a city. Brand image of dragon boat race not only conveys emotional value but also is the overall impression in participants' mind, which contributes to promote city's overall image and improve city's development constantly. During experiencing the culture, we can create a set of values that is extremely important in getting your brand image known by natives and foreigners $t$ and build a platform of dragon boat culture from which everyone can enjoy the activities concerned [6].

\section{The Function of Education}

- Patriotism is the core of dragon boat culture which is formed gradually with the development of society and economy. In the course of forming dragon boat culture, it is endowed with new and positive content and becomes patriotism culture that is core value for those who are loyal to their country and make self-sacrifice.

- Unity and progress is the goal of dragon boat culture. Dragon boat culture advocates collectivism, which shows the spirit of unity and progress during the dragon boat race. The significant feature of dragon boat race is that all participants join the activities regardless their ability, knowledge, degree, social class, height and weight. The participants are a unity who work together to win the race. So dragon boat race can have a positive influence on building the spirit of cooperation and competition. It represents team spirit and collective strength is greater than that of individual.

- It has been a long-standing tradition for dragon boat culture to be used to value education and respect patriotism in China. From ancient times, Chinese people have been paying much attention to dragon boat culture, especial for it's the educational significance. Since education is so highly respected in China, men who have mastered much knowledge would have a higher social status and be esteemed by other people. Patriotism is the one of the traditional virtues of China and it is regarded as an obligatory duty in China. Chinese people believe that only those who are concerned with and practice hearted devotion to nation would be honest, faithful, and be grateful to others and seek ways to return their kindness. So conveying the dragon boat culture is an entrance to promoting citizens' traditional culture awareness and showing its educational connotation.

In summary, dragon boat culture has an effect on education in the aspect of patriotism and unity and progress. 


\section{Protecting Ecology Environment}

Dragon boat activities concerned need a sound water ecology environment. It is impossible for us to develop and expand the dragon boat culture if there is no good ecology environment. Dragon boat culture is relevant to the water quality. But water pollution, together with the economic development at high speed, takes place in most of areas, which has a negative impact on dragon boat culture. In this case, we must manage to control water pollution and bring other pollution under control [7]. After joining relevant dragon boat culture activities, we have realized ecology environment have been affecting human living space and harmonious relationship is being made up between human being and nature that is presented by traditional culture. Thus, dragon boat culture has the function of protecting ecology environment, maintain ecology balance and keep sustainable development. We should manage to explore the implications of dragon boat culture in order to make it play an important role of the world culture. So we'd better take measures as following:

- Take effective measures to minimize the pollution is the demand of spreading dragon boat culture.

- Take pains to develop tourism and other relevant industries that are beneficial to the protection of the ecological environment.

- Strengthen evaluation and management of the quality of water and major infrastructure construction projects on the ecology environment.

\section{E. Improving Physical and Mental Health}

Dragon boat race is the main content of dragon boat culture. It can improve heart blood circulation effectively when paddling. During the paddling, the participants can increase the function of internal organ through bearing exercise for a long period of time, for example improving the strength of heart contraction, the function of respiratory system and circulatory system etc. The paddling can strength up body muscles and can contribute to the treatment and recovery of patients with breast cancer. The technical characteristic of dragon boat race is the rhythm of paddling, which makes participants listen to the order carefully and get the sound judgment to promote the function of human sensory organ, the flexibility of central nervous and the ability to motor center controlling human organ [8]. Dragon boat paddlers, canoeists, and rafters all require core strength, upper body endurance, coordination and flexibility. Paddling exercises do need less leg strength than rowing but it is important to possess overall fitness so that participants can maximize performance of paddling boat.

Participants must join functional fitness training and improve core and upper body strength that is required in course of paddling a boat, which can increase the amount and frequency of taking exercise before join the activities of dragon boat race and be helpful to recover from the cancer [9].
In the past, patients with breast cancer protected themselves from doing any upper body exercise only because they concerned about lymphedema, a sometimes incapacitating swelling of the arm. But later, we realized that dragon boating is helpful to make the patients recover from the cancer through strenuous repetitive upper body motion. Besides, the following are other effects of dragon boating as for patients with breast cancer.

- Encourage women who have been diagnosed with breast cancer to lead positive and active lives for dragon boat culture has the characteristic of marching forward courageously.

- Demonstrate the benefits of an active lifestyle through the sport of dragon boating since dragon boat culture highlights the solidarity and collectivism and participants can help and encourage with each other during dragon boating.

- Raise awareness about the recovery of breast cancer and motivate the participants to increase the confidence in the pursuit of a cure.

- Offer support and fellowship to team members and enjoy paddling the dragon boat.

Apart from its spiritual benefits, participants who are accustomed to paddling dragon boat demonstrate some physical and psychological benefits of survivors who have been diagnosed as breast cancer including:

- Improve the motion of participants with breast cancer after post-surgical range without damaging the adjacent healthy tissues.

- Enhance muscular and skeletal strength through repeating paddling.

- Increase immune system with the means of physiological function.

- Promote an awareness of mental health wellness and provide some entrances to improving both mental and overall physical wellness. Relieve stress and develop lifestyle behaviors and set realistic life goals that help participants with breast cancer to improve mental health wellness in both body and mind.

\section{SUMMARY}

In summary, the dragon boat culture is the concentrated embodiment of Chinese traditional culture, it represents marching forward courageously and valiant patriotism, which has a strong educational significance and which is a vivid miniature of the spirit and development of the times. Dragon boat culture plays an important role of improving the sustainable development of society, economy and ecology environment. As a result, it is the collective responsibility to promote and popularize dragon boat culture all over the world. 


\section{ACKNOWLEDGMENT}

Firstly, I have to say thanks to my colleagues and friends who support me for a long time and who have looked over my thesis with patience and given me instructive suggestions. Secondly, I extremely appreciate my family's support.

I really appreciate Professor Cong Qun's support. Professor Cong is the dean of Physical Education Department of Shanghai Polytechnic University. Thanks to his guidance and encouragement, I finish the paper finally after he look over my paper and give some good pieces of advice. Without his patient and consistent instruction, this paper could not have been finished its present form.

What's more, I would like to express my most heartfelt thanks to Professor Deng Jiangping, who teach me how to get the information on international conference and translate from Chinese into English.

\section{REFERENCES}

[1] Huangjiang Zhang and Xiaodong Wang, "Culture Features and Social Functions of Folk Sports in Hanshui Basin," Journal of Journal of Guangzhou Sport University, vol. 35, No. 2, pp. 21-23, Mar. 2015.

[2] Jianfeng Lin, "Research on Development of Dragon Boat Races in Fujian and Taiwan Colleges," Sports Science Research, vol. 19, No. 1, pp. 10-13, Jan. 2015.

[3] Saojun Lu and Gang Dai, "Non-material Culture Heritage of Dragon Canoes of Miao Nationality in Guizhou," Journal of Wuhan Institute of Physical Education, vol.45 No.6, pp.69-74, Jun. 2011.

[4] Hongshen Wang, "Ecological Adaptation of Chinese Dragon-Boat Culture Evolution," Journal of Beijing Sport University, vol.40 No.6, pp.134-138, Jun. 2017.

[5] Ke Zhang, "A Research on Talent Demands of Chinese Dragon Boat Sports Cultural Inheritance and Its Cultivation Strategy," Journal of Guangzhou Sport University, vol.36 No.5, pp.84-87, Sept. 2016.

[6] Yike Ni, "Socio-Culture Research on Modern China 'Dragon Boat Phenomenon," Journal of Journal of Chengdu Sport University, vol.27 No.6, pp.23-26, Sept. 2001.

[7] Fuxiang Dai, "Cultural Refection of the Development of Modern Dragon Boat Sport_— based on the real dragon-boat Racing in Border Tow", Journal of Chengdu Physical Education Institute, vol. 37 No.11,pp49-52, Nov. 2011.

[8] Yuping, "Influence of Dragon Boat Sport Curriculum Setting up on College Campus Sports Culture", Bulletin of Sport Science \& Technology, vol. 22 Nov. 9, pp99-100, 2014.

[9] Wei Song, "Study on Tendency and Status quo of Chinese Traditional Sports Culture", Journal of Journal of Guangzhou Sport University, vol.26 No.4, pp94-96, Apr. 2006. 